\title{
Kesejahteraan Spiritual pada Mahasiswa Penghafal Al-Qur'an
}

\author{
Widwi Mukhabibah, Retno Hanggarani Ninin, Poeti Joefiani ${ }^{1}$ \\ Universitas Padjajaran, Bandung
}

\begin{abstract}
Nowadays, memorizing the Qur'an is growing and interested by children to adults, including college students. The activity is interesting because in the perspective of Islamic Shari'ah, memorizing the Qur'an is not an obligation. Therefore, in psychological science, it will be useful to find any factors that encourage students to do so. An initial survey found that students had belief associated with the spiritual domain of divinity and felt calm when memorizing the Qur'an. Those factors will be studied in the concept of spiritual well-being by Ellison (1983). This quantitative study was conducted on students at Universitas Padjadjaran. There were 40 students selected with snowball sampling. The result showed that as many as $85 \%$ of students had high spiritual well-being. It showed that the majority of students have a harmonious and stable life indicated by the closeness with Allah SWT and life satisfaction.
\end{abstract}

Kata Kunci: Spiritual Well-Being; Penghafal Al-Qur'an; Religious Well-Being; Existential Well-Being.

\section{Pendahuluan}

Religiusitas dan spiritualitas telah menjadi bagian dari sejarah kehidupan manusia. Keduanya telah menjadi subjek dan objek dari seni, musik, puisi, budaya, dan aktivitas manusia lainnya. ${ }^{2}$ Pada awalnya terdapat pandangan bahwa agama/spiritualitas tidak dianggap sebagai bidang penelitian psikologi. ${ }^{3}$ Padahal menurut Fontana ${ }^{4}$, aspek spiritual sebenarnya adalah salah satu kebutuhan manusia yang mendasar. Kemudian muncul masa dimana para positivist, mengkaji mengenai konstruk seperti agama, spiritualitas, spiritual well-being dan sebagainya hingga konstruk ini menjadi bagian dari kajian positive psychology. ${ }^{5}$

\footnotetext{
${ }^{1}$ Korespondensi untuk tulisan ini ditujukan kepada email emailwiwit@gmail.com

${ }^{2}$ Raymond F. Paloutzian and Crystal L. Park, Handbook of the Psychology of Religion and Spirituality (New York: The Guilford Press, 2005). 21-42

${ }^{3}$ B. Van Rooyen and R. B. I. Beukes, Narrating Spiritual Well-Being in Relationship to Positive Psychology and Religion, 2009. 21-42

${ }^{4}$ Rostiana, "Pengaruh Kebahagiaan Integratif Terhadap Komitmen Organisasional Dan Perilaku Kewargaan Organisasional" (Disertasi, Universitas Padjajaran Bandung, 2011).

${ }^{5}$ lbid.
} 
Spiritualitas terkait dengan kepercayaan terhadap kekuasaan yang ghaib, kedekatan dengan Tuhan atau kekuasaan supernatural. Sementara religi lebih dikaitkan dengan institusi, ajaran, atau doktrin keagamaan. ${ }^{6}$ Spiritual mencerminkan ekspresi internal sedangkan religi mencerminkan ekspresi eksternal. Di satu sisi religi dipandang sebagai sesuatu yang formal, institusional, dogmatis, otoritarian dan menghambat ekspresi. Di sisi lain, spiritual direpresentasikan dengan sesuatu yang bersifat individual, subyektif, tidak sistematik dan bebas diekspresikan. Dalam kehidupan nyata, sebagian besar orang merasakan pengalaman spiritualnya dalam konteks pelaksanaan religi. Jadi, pada dasarnya religi dan spiritual memang berbeda, namun dalam praktiknya kedua konsep tersebut sangat terkait erat. ${ }^{7}$

Salah satu konstruk yang sangat terikat dengan spiritualitas adalah spiritual wellbeing. ${ }^{8}$ Selain itu, sejumlah studi dengan partisipan yang berasal dari Barat (western) menyatakan bahwa spiritual well-being memiliki korelasi positif dengan religiusitas dan keyakinan serta praktik spiritual (spiritual beliefs and practices). ${ }^{9}$

Pada awal mula perkembangannya, Ellison (1983) menjelaskan bahwa spiritual wellbeing dibangun oleh dua kondisi yaitu kondisi religious well-being (RWB) dan existential wellbeing (EWB). Religious well-being merupakan persepsi individu terhadap hubungannya dengan Tuhan (Sang Pencipta / kekuatan yang lebih tinggi), sedangkan existential well-being merupakan persepsi individu mengenai makna hidup atau tujuan serta kepuasan hidupnya terlepas dari aspek keagamaan. ${ }^{10}$

Secara umum, spiritual well-being memiliki korelasi positif dengan tujuan hidup, selfesteem, dan intrinsic religious commitment. ${ }^{11}$ Dalam kaitannya dengan religious commitment atau religiusitas, Glock ${ }^{12}$ menyatakan bahwa konsep religiusitas yang dibangunnya relatif independen dan dapat mencakup seluruh kemungkinan ekspresi religi dari agama-agama yang ada di dunia, termasuk Islam.

\footnotetext{
${ }^{6}$ Ibid.

${ }^{7}$ Ibid.

${ }^{8}$ Panagiota Darvyri et al., "The Spiritual Well-Being Scale (SWBS) in Greek Population of Attica," Psychology 5, no. 13 (2014): 1575-1582.

${ }^{9}$ Ahmad Musa, "Spiritual Beliefs and Practices, Religiosity, and Spiritual Well-Being Among Jordanian Arab Muslim University Students in Jordan," Journal of Spirituality in Mental Health 17, no. 1 (2015): 34-49.

${ }^{10}$ Verna Hendricks-Ferguson, "Relationships of Age and Gender to Hope and Spiritual Well-Being among Adolescents with Cancer," Journal of Pediatric Oncology Nursing 23, no. 4 (2006): 189-199.

11 Ibid. 189-199

${ }^{12}$ Yasemin El-Menouar, "The Five Dimensions of Muslim Religiosity. Results of an Empirical Study," methods, data, analyses 8, no. 1 (2014): 26.
} 
Agama Islam memiliki pedoman atau kitab suci, yakni Al-Qur'an. Dalam agama Islam terdapat rukun iman, yakni percaya kepada Allah SWT, malaikat-malaikat Allah, kitab-kitab Allah, rasul-rasul Allah, Hari Kiamat, serta ketetapan (Qada dan Qadar) Allah. Hal tersebut menunjukkan bahwa setiap penganut agama Islam wajib bersikap percaya atau yakin akan kebenaran Al-Qur'an, dimana Al-Qur'an merupakan kitab dari Allah SWT. Peneliti mengidentifikasi bahwa selain sikap percaya akan kebenaran isi Al-Quran, ada perilaku tertentu yang dilakukan oleh penganut agama Islam, yaitu membaca, mempelajari, menghafalkan dan mengamalkan Al-Qur'an.

Terkait dengan menghafal Al-Qur'an, saat ini sedang berkembang aktivitas menghafal Al-Qur'an. Dikutip dari kabarmakkah.com¹3, gerakan menghafal Al-Qur'an sedang mengalami perkembangan yang pesat. Hal ini dapat terlihat dari diberlakukannya studi hifz (menghafalkan) Al-Qur'an menjadi mata pelajaran wajib di sejumlah SDIT, SMIT, SMAIT bahkan Perguruan Tinggi Negeri maupun Swasta. Selain itu, di sejumlah daerah telah bermunculan pondok pesantren tahfizh Al-Qur'an dan diadakan lomba menghafal AlQur'an di berbagai tingkatan. Saat ini bahkan beberapa Perguruan Tinggi menyediakan jalur khusus dan memberikan beasiswa kepada para penghafal Al-Qur'an untuk melanjutkan pendidikannya. Beberapa hal tersebut membuat jumlah penghafal Al-Qur'an khususnya di Indonesia meningkat. Dilansir dari republika.co.id ${ }^{14}$, jumlah penghafal AlQur'an pada tahun 2010 mencapai 30.000 penghafal, lebih banyak dari Arab Saudi yang berjumlah 6.000 penghafal.

Menghafalkan Al-Qur'an dapat dijelaskan sebagai proses encoding (menyandikan), storing (menyimpan), dan retrieving (memanggil atau mengambil kembali) ayat Al-Qur'an dengan berlatih dan mengulangi ayat tersebut berkali-kali. Proses ini dapat disebut dengan Hifz. Hifz meliputi proses penyandian pertama dari ayat Al-Qur'an dengan memberikan perhatian terhadapnya, kemudian menyimpannya dengan cara mempertahankan

\footnotetext{
${ }^{13}$ Kabar Makkah, "Ini 15 Fakta Mengapa Gerakan Menghafal Qur'an Di Indonesia Meningkat," accessed June 25, 2016, http://www.kabarmakkah.com/2016/05/ini-15-fakta-mengapa-gerakan-menghafal-quranberkembang-pesat.html?m=1.

14 Republika, “Jumlah Penghafal Al-Qur'an Indonesia Terbanyak Di Dunia," accessed June 25, 2016, http://www.republika.co.id/berita/dunia-islam/islam-nusantara/10/09/24/136336-jumlah-penghafal-alquranindonesia-terbanyak-di-dunia.
} 
(maintaining) informasi yang telah disandikan, lalu 'memanggil' (retrieving) informasi yang sudah disimpan. ${ }^{15}$

Fenomena meningkatnya aktivitas menghafal Al-Qur'an ini juga terjadi di kalangan mahasiswa. Tidak terkecuali mahasiswa Universitas Padjadjaran. Peneliti mengamati bahwa sekitar 1 tahun terakhir mulai berkembang kelompok-kelompok tahfizh (penghafal Al-Qur'an) di lingkungan Universitas Padjadjaran. Kelompok tahfizh ini biasanya berada di bawah naungan lembaga dakwah (atau kelompok keagamaan fakultas) karena merupakan salah satu program kerjanya atau sebagai bentuk penjagaan rohani terhadap pengurus lembaga dakwah tersebut. Kegiatan menghafal Al-Qur'an merupakan hal menarik karena dalam ajaran Islam, menghafal Al-Qur'an bukanlah sebuah kewajiban. Maka ketika seseorang memutuskan untuk melakukannya, akan bermanfaat dalam keilmuan psikologi untuk bisa menemukan faktor-faktor yang membuat seorang individu mau melakukannya.

Berdasarkan hasil survey peneliti menggunakan kuesioner yang disebar secara online, diketahui bahwa motivasi yang paling banyak mendasari responden untuk menghafal AlQur'an adalah keyakinan akan ganjaran (keutamaan) yang dijanjikan bagi penghafal AlQur'an yaitu dapat memberi mahkota untuk kedua orang tuanya di surga ${ }^{16}$, meyakini bahwa dirinya seperti menjadi keluarga Allah SWT ${ }^{17}$, serta mendapatkan syafaat (pertolongan) dari Al-Qur'an di akhirat ${ }^{18}$. Selain itu, sebagian besar responden merasakan adanya ketenangan saat melakukan proses menghafal. Hal ini sejalan dengan keterangan dalam Al-Qur'an bahwa membaca atau menghafal Al-Qur'an sebagai sarana mengingat Allah (zikrullah) akan membuat hati menjadi tentram ${ }^{19}$. Meskipun responden sempat mengalami kesulitan dalam menghafal dan sulit memotivasi dirinya namun ketika berhasil menghafal ayat Al-Qur'an timbul rasa tenang. Peneliti berpendapat bahwa "rasa tenang" tersebut merupakan agregat psikologis yang dalam psikologi dikonseptualisasi sebagai kesejahteraan psikis atau well-being. Oleh karena kondisi well-being tersebut melibatkan aspek Tuhan maka berada dalam domain spiritual.

\footnotetext{
${ }^{15}$ Nazia Nawaz and Syeda Farhana Jahangir, "Effects of Memorizing Quran by Heart (Hifz) on Later Academic Achievement," Journal of Islamic Studies and Culture 3, no. 1 (2015): 58-64.

${ }^{16}$ Seperti dalam Hadits Riwayat Al- Hakim

17 Seperti dalam Hadits Riwayat Ahmad

18 Seperti dalam Hadits Riwayat Muslim No. 1910

${ }^{19}$ Seperti dalam Terjemah Al-Qur'an Surah Ar-Ra'd (13) ayat 28
} 
Individu yang menghafalkan Al-Qur'an tentu memiliki alasan tersendiri ketika melakukannya sehingga lebih bersifat personal (private). Dalam melakukannya pun, individu tidak terikat dengan aturan baku tertentu sehingga bersifat informal. Jenis ritual (ibadah) yang personal dan informal seperti ini termasuk ke dalam dimensi ritualistik tepatnya subdimensi devotion dalam teori religiusitas menurut Glock. ${ }^{20}$

Hassan $^{21}$ menyatakan bahwa devotionalism merupakan indikator yang menunjukkan bahwa religious commitment atau religiusitas seseorang itu tinggi. Maka dari itu, perilaku menghafal Al-Qur'an yang termasuk ke dalam religious devotion mengindikasikan bahwa pelakunya memiliki religiusitas yang tergolong tinggi. Hal tersebut menandakan bahwa individu memiliki hubungan yang dekat dengan Tuhannya.

Menghafal Al-Qur'an juga menandakan adanya partisipasi seseorang terhadap agamanya dalam bentuk perilaku. Religious participation merupakan bagian dari spiritual practice. 22 Dalam studinya, Butt menyatakan bahwa spiritual practice dapat meningkatkan well-being dan menurunkan distress serta menaikkan skor life purpose dan life satisfaction. ${ }^{23}$

Oleh karena itu, untuk mendapatkan fakta sesungguhnya mengenai kesejahteraan pada penghafal Al-Qur'an maka perlu dikaji lebih lanjut mengenai gambaran spiritual wellbeing pada mahasiswa penghafal Al-Qur'an di Universitas Padjadjaran.

\section{Metode}

Penelitian ini berfokus pada pengukuran kesejahteraan spiritual (spiritual well-being) Penelitian ini termasuk ke dalam kategori penelitian deskriptif. Penelitian deskriptif berfokus pada menjelaskan atau menggambarkan fenomena, peristiwa, atau situasi tertentu ${ }^{24}$. Prosedur penelitian yang digunakan dalam penelitian ini adalah paper-and-pencil yakni menggunakan kuesioner serta menggunakan concurrent procedures, dimana peneliti

\footnotetext{
${ }^{20}$ El-Menouar, "The Five Dimensions of Muslim Religiosity. Results of an Empirical Study."

${ }^{21}$ Riaz Hassan, "On Being Religious: Patterns of Religious Commitment in Muslim Societies," The Muslim World 97, no. 3 (2007): 437-478.

${ }^{22}$ Naseer Butt, "Spiritual Well-Being in Relation to General Health among Kashmiri Students," Public Research (2013).

23 Ibid.

${ }^{24}$ L. B. Christensen. Experimental Methodology, 10th edition (USA : Pearson Education Inc, 2007), 39.
} 
mengumpulkan data kuantitatif dan kualitatif dalam waktu yang sama dengan tujuan untuk menyajikan analisis yang komprehensif (menyeluruh) terhadap masalah penelitian. ${ }^{25}$

\section{Partisipan Penelitian}

Partisipan penelitian ini adalah mahasiswa/i Universitas Padjadjaran berstatus aktif jenjang sarjana (S1), beragama Islam, dan menghafalkan Al-Qur'an. Peneliti menggunakan teknik pengambilan sampel bola salju (snowball sampling). Jumlah partisipan penelitian ini adalah 40 orang, terdiri dari 20 orang perempuan dan 20 orang laki-laki.

\section{Instrumen Penelitian}

Alat ukur yang digunakan dalam penelitian ini adalah kuesioner Spiritual Well-Being Scale (SWBS) dalam bentuk terjemahan Bahasa Indonesia. Alat ukur tersebut diambil dari penelitian Tuti Anggraini Utama ${ }^{26}$ yang sebelumnya diterjemahkan dari alat ukur aslinya yaitu Spiritual Well-Being Scale (SWBS) dari Paloutzian \& Ellison (1983). Terdapat 20 aitem dalam alat ukur ini, terdiri dari 10 aitem yang mengukur religious well-being dan 10 aitem yang mengukur existential well-being. Setiap aitem terdiri dari 6 pilihan skala dan responden diharuskan memilih skala yang paling sesuai dengan dirinya. Setelah mendapatkan alat ukur peneliti kemudian menambahkan kolom kosong pada setiap aitem dimana setiap responden akan diminta menjelaskan alasan pemilihan skala pada setiap aitem (data kualitatif). Alasan yang dituliskan oleh responden ditujukan untuk menggali informasi yang lebih dalam terkait aitem-aitem pada dimensi religious well-being (RWB) dan existential well-being (EWB). Nilai reliabilitas alat ukur ini adalah 0.863 dan termasuk dalam kriteria dapat diandalkan dan konsisten menurut Kaplan dan Saccuzo. ${ }^{27}$

Hasil pengukuran kuesioner SWBS diolah dengan menjumlahkan setiap skor dari masing-masing pernyataan yang mewakili setiap dimensi. Dengan demikian akan diperoleh skor dari setiap dimensi dan skor total spiritual well-being. Hasil pengolahan data berupa skor SWBS dibagi ke dalam tiga kategori yaitu kategori rendah, sedang, dan tinggi.

\footnotetext{
${ }^{25}$ John W. Cresswell, Research Design Qualitative, Quantitative, and Mixed Methods Approaches, 2nd Edition (USA: Sage Publications Inc, 2003). 16

${ }^{26}$ Tuti A. Utama, “Perbedaan Kesejahteraan Spiritual Pasien Sebelum Dan Sesudah Operasi Jantung Di RSUP Dr. Hasan Sadikin Bandung” (Tesis, Universitas Padjajaran Bandung, 2015).

${ }^{27}$ R. M. Kaplan and Demis P. Saccuzo, Psychological Testing: Principles, Application, and Issues, 5th Edition (Belmont: Wadsworth, 2001).
} 


\section{Hasil}

Sebagian besar responden yakni penghafal Al-Qur'an menunjukkan kondisi spiritual well-being yang tinggi. Tidak ada responden yang menunjukkan kondisi SpWB yang rendah (Tabel 1).

Tabel 1

Gambaran Umum Spiritual Well-Being pada Penghafal Al-Qur'an

\begin{tabular}{ccc}
\hline Kategori SpWB & Jumlah Responden & Persentase \\
\hline Rendah & 0 & $0 \%$ \\
Sedang & 6 & $15 \%$ \\
Tinggi & 34 & $85 \%$ \\
Total & 40 & $100 \%$ \\
Nilai rata-rata kelompok & 90,98 (termasuk ke dalam kategori tinggi) \\
\hline$X=90.98$ SD $=9.691$ & &
\end{tabular}

Diagram 1

Gambaran SpWB berdasarkan Sebaran Dimensinya

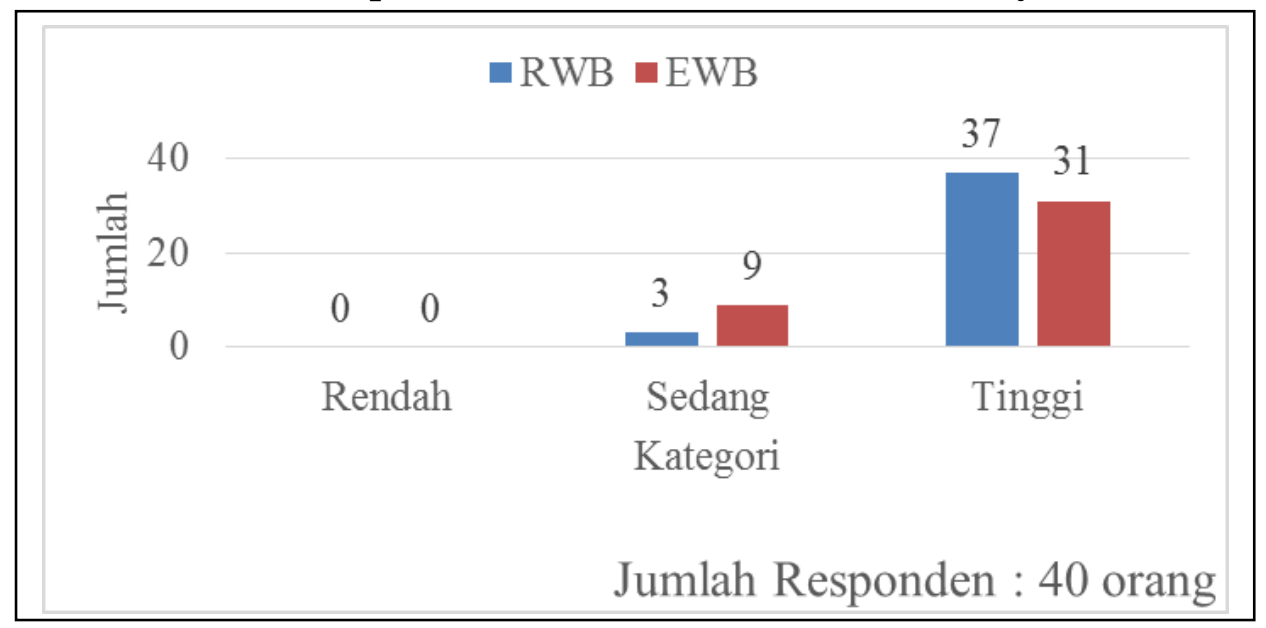

Jika dilihat berdasarkan dimensi-dimensi yang membangunnya, pada dimensi RWB, 7.5\% (3 orang) memiliki skor yang termasuk ke dalam kategori sedang dan 92.5\% (37 orang) memiliki skor yang termasuk ke dalam kategori tinggi. Pada dimensi EWB, 22.5\% (9 orang) memiliki skor yang termasuk ke dalam kategori sedang dan 77.5\% (31 orang) memiliki skor yang termasuk ke dalam kategori tinggi. Tidak ada skor dimensi yang masuk ke dalam kategori rendah (Diagram 1).

Selain itu, berdasarkan perhitungan statistik, perbedaan data demografi yang digunakan tidak berpengaruh pada variasi data yang muncul. Hal ini tergambar dalam tabel 2. 
Tabel 2

Hasil Uji Beda Nilai SpWB berdasarkan Data Demografi

\begin{tabular}{c|ccc}
\hline Data Demografi & \multicolumn{3}{c}{ Nilai $\mathbf{p}\left(\right.$ Ket $: \mathbf{p}<\mathbf{0 . 0 5}=\mathbf{H}_{\mathbf{0}}$ ditolak, terdapat perbedaan) } \\
\cline { 2 - 4 } & $\mathbf{R W B}$ & EWB & $\mathbf{S W W B}$ \\
\hline Jenis Kelamin & 0.351 & 0.269 & 0.446 \\
Lama Menghafal & 0.234 & 0.480 & 0.587 \\
Jumlah Hafalan & 0.790 & 0.504 & 0.458 \\
Jenis Hafalan & 0.784 & 0.537 & 0.306 \\
$\quad$ Jadwal & 0.240 & 0.623 & 0.246 \\
Menghafal & & & 0.795 \\
Metode & 0.066 & 0.193 & \\
Menghafal & & & 0.120 \\
Dorongan & 0.064 & 0.116 & \\
Menghafal & & & \\
\hline
\end{tabular}

Catatan $:$ RWB $=$ Religious Well-Being, EWB = Existential Well-Being, SpWB = Spiritual WellBeing

\section{Diskusi}

Sebelumnya perlu diketahui bahwa peneliti adalah seorang penghafal Al-Qur'an sehingga memiliki karakteristik yang dapat menempatkan peneliti sebagai responden. Kedekatan antara peneliti dengan responden menjadi tantangan tersendiri bagi peneliti untuk tetap objektif dalam melakukan penelitian. Oleh karena itu, terdapat kemungkinan adanya bias dalam analisis data, hasil, pembahasan, serta kesimpulan penelitian sebagai akibat dari kondisi tersebut.

Skor SpWB yang diperoleh oleh responden penelitian yakni penghafal Al-Qur'an di Universitas Padjadjaran berkumpul di dua kategori, yakni tinggi dan sedang. Ketidakberadaan skor yang termasuk kategori rendah menggambarkan bahwa secara umum responden merasakan adanya kondisi sejahtera secara spiritual dalam kehidupan mereka.

Responden yang termasuk ke dalam kategori SpWB tinggi ternyata memiliki skor dimensi RWB dan EWB yang juga tergolong tinggi. Begitupun dengan responden yang termasuk ke dalam kategori SpWB sedang memiliki skor dimensi yang tergolong sedang pula. Terdapat sejumlah perbedaan keyakinan dan perilaku pada kedua kategori SpWB. Perbedaan ini dapat dilihat pada tabel 3.

Setelah menggambarkan bagaimana perbedaan keyakinan dan perilaku antara responden dengan skor SpWB sedang dan skor SpWB tinggi, peneliti mencoba menganalisis 
adakah perbedaan pada responden berdasarkan kombinasi dari dua skor dimensi, yaitu skor religious well-being (RWB) dan existential well-being (EWB). Berdasarkan pengolahan data, kombinasi skor dimensi dibagi menjadi tiga kategori, yaitu (1) RWB tinggi dan EWB tinggi, (2) RWB tinggi dan EWB sedang, serta (3) RWB sedang dan EWB sedang. Perbedaan ini ditunjukkan dalam tabel 4 .

Selanjutnya peneliti mencoba menganalisis bagaimana variasi SpWB responden berdasarkan data demografi yang diperoleh. Dalam pengolahan data demografi peneliti menemukan sebuah pola. Responden yang memiliki skor spiritual well-being yang tinggi didominasi oleh metode menghafal dengan mengikuti lembaga tahfizh, memiliki jadwal yang tentatif (berubah-ubah), serta dorongan untuk menghafal Al-Qur'an bersumber dari dirinya sendiri. Sedangkan responden yang memiliki skor spiritual well-being yang sedang didominasi oleh responden yang jadwal menghafalnya tentatif (berubah-ubah) serta dorongan menghafal yang bersumber dari orang tua dan penghafal Al-Qur'an yang lain/idolanya. Sedangkan pada kategori ini, variasi metode menghafalnya seimbang antara yang otodidak (menghafal sendiri), mengikuti lembaga tahfizh, maupun mengikuti kelompok tahfizh non-institusi. 
Tabel 3

Matriks Perbedaan Keyakinan dan Perilaku Responden berdasarkan Skor SpWB

\section{Spiritual Well-Being Sedang}

- Meyakini kebenaran dan kepastian asmaul husna (nama-nama yang baik yang dimiliki Allah)

- Banyak berdo'a

- Melakukan aktivitas kebaikan ; menegur orang yang berbuat kesalahan

- Menikmati lingkungan sosial di sekitarnya

- Meyakini ujian/cobaan itu datang sesuai dengan kemampuan individu

- Kondisi keimanan yang naik-turun/futur (misalnya dilihat dari kualitas dan kuantitas ibadah yang naik-turun, kesulitan dalam menyesuaikan diri di lingkungan yang menyebabkan kurang semangat beribadah) menyebabkan perasaan belum memiliki hubungan yang bermakna dengan Allah

- Situasi sepi (sendiri) sebagai sarana mendekatkan diri kepada Allah

- Mengenal diri sendiri, namun belum semuanya mengetahui tujuan hidup

- Merasa hidup adalah sesuatu yang berharga

- Mengambil pelajaran dari pengalaman positif maupun negatif (meski belum semua responden seperti ini)

- Belum puas dan tidak terlalu menikmati kehidupannya karena merasa masih banyak kekurangan diri

- Belum mantap/ragu-ragu dengan masa depannya karena malas untuk berubah, merasa banyak kekurangan, dan takut Allah tidak memberkahi kehidupannya

- Konflik bisa menimbulkan ketidakbahagiaan, tapi juga sebagai sarana mendapatkan ilmu

\section{Spiritual Well-Being Tinggi}

- Meyakini bahwa Allah mengasihi hamba-Nya dengan cara mengabulkan do'a, memberi kesehatan, dan rezeki lainnya

- Meyakini kebenaran dan kepastian asmaul husna (nama-nama yang baik yang dimiliki Allah)

- Meyakini bahwa Allah memberikan kekuatan dan dukungan kepada hamba-Nya melalui pertolongan-Nya

- Meyakini bahwa ujian/cobaan datang sebagai sarana untuk menguatkan hamba-Nya

- Menjadikan Allah sebagai 'tempat curhat' dan 'pegangan' dalam hidup

- Melibatkan Allah dalam segala aspek kehidupan

- Mendekatkan diri kepada Allah melalui ibadah baik yang wajib maupun sunnah

- Banyak berdo'a dan merenung

- Saat mengalami futur (contohnya kualitas dan kuantitas ibadah yang menurun), muncul perasaan tidak nyaman misalnya merasa banyak masalah, hampa, kesepian, dan sebagainya. Namun perasaan tidak nyaman tersebut sebagai 'panggilan' agar manusia kembali ke dalam aktivitas ibadah yang seharusnya

- Melakukan hal positif saat sedang sendiri, misalnya beribadah

- Berinteraksi dengan orang lain agar hidup semakin terasa lengkap

- Mengenal diri dan mengetahui tujuan hidup (berasal dari Al-Qur'an, majelis/kajian ilmu, nasihat orang tua) meski belum semua responden ada dalam kondisi tersebut

- Merasa bahwa hidup adalah pengalaman yang berharga, pengalaman baik maupun buruk dapat dijadikan pembelajaran

- Menikmati hidup dengan mencoba memberi makna pada tiap peristiwa 
- Mengajak dan mengingatkan orang lain kepada aktivitas kebaikan, memberi manfaat pada sesama serta meyakini bahwa Allah selalu mengawasi dapat membuat hidup lebih bermakna.
- Ketika merasa tidak puas, maka mencoba bersyukur dan berusaha tetap menikmati peristiwa yang hadir sehingga muncul kepuasan

- Ketika merasa ragu dengan masa depan maka berprasangka baik (husnudzon), berusaha maksimal disertai berdo'a maka akan memunculkan rasa optimis terhadap masa depan

- Menghadapi masa depan dengan berpedoman pada Al-Qur'an dan Hadits dan menjaga keimanan (misalnya menjaga kualitas ibadah)

- Memandang konflik sebagai ujian, cara untuk bisa menikmati hidup, serta sarana untuk mengembangkan dan memperbaiki diri

- Menghayati peran-peran yang dijalani dapat membuat hidup menjadi terasa bermakna. 
Tabel 4

Matriks Perbedaan Kategori RWB-EWB pada Responden

\begin{tabular}{|c|c|c|c|c|}
\hline Dimensi & $\begin{array}{l}\text { Aspek / } \\
\text { Situasi }\end{array}$ & RWB Tinggi-EWB Tinggi & RWB Tinggi-EWB Sedang & RWB Sedang-EWB Sedang \\
\hline $\begin{array}{l}\text { Religious } \\
\text { Well- } \\
\text { Being }\end{array}$ & $\begin{array}{l}\text { Hubungan } \\
\text { yang } \\
\text { bermakna } \\
\text { dengan Allah } \\
\text { SWT }\end{array}$ & $\begin{array}{l}\text { Merasa Allah selalu membantu dan } \\
\text { mengawasi. Allah sebagai sarana } \\
\text { 'curhat' yang terbaik, segala sesuatu } \\
\text { yang melibatkan Allah pasti } \\
\text { bermakna, ada keyakinan jika kita } \\
\text { mendekatkan diri pada Allah maka } \\
\text { Allah pun akan dekat hambaNya }\end{array}$ & $\begin{array}{l}\text { Responden menyatakan ketika } \\
\text { merasa dekat dengan Allah / } \\
\text { merasa sedang giat beribadah, } \\
\text { timbul perasaan yang positif } \\
\text { seperti tentram, nyaman, merasa } \\
\text { akan ditolong / dikabulkan } \\
\text { doanya, dan tidak kesepian }\end{array}$ & $\begin{array}{l}\text { Responden menyatakan kondisi } \\
\text { iman mereka sering naik-turun atau } \\
\text { futur (lemah), ditandai dengan } \\
\text { kualitas ibadah yang dirasa masih } \\
\text { kurang baik sehingga belum } \\
\text { merasakan adanya hubungan yang } \\
\text { bermakna }\end{array}$ \\
\hline \multirow[t]{2}{*}{$\begin{array}{l}\text { Existenti } \\
\text { al Well- } \\
\text { Being }\end{array}$} & $\begin{array}{l}\text { Kepuasan } \\
\text { terhadap } \\
\text { kehidupan } \\
\text { yang sedang } \\
\text { dijalani }\end{array}$ & $\begin{array}{l}\text { Responden menikmati hidupnya } \\
\text { dengan segala hal yang harus } \\
\text { dihadapi serta mencoba } \\
\text { memaknakan setiap peristiwa. } \\
\text { Terkadang responden masih } \\
\text { merasakan ketidakpuasan dalam } \\
\text { hidupnya saat ini, namun diiringi } \\
\text { rasa syukur dan usaha untuk } \\
\text { menikmati, maka akan muncul } \\
\text { perasaan puas. }\end{array}$ & $\begin{array}{l}\text { Mayoritas merasa belum puas, } \\
\text { namun ada kesadaran untuk } \\
\text { terus berprasangka baik } \\
\text { (husnudzon) dan untuk berusaha } \\
\text { dengan lebih baik }\end{array}$ & $\begin{array}{l}\text { Mayoritas merasa belum puas, dan } \\
\text { pernyataan responden berfokus } \\
\text { pada kegagalan atau } \\
\text { ketidakpunyaan atas kemampuan } \\
\text { tertentu. Secara kognitif menyadari } \\
\text { seharusnya ada perubahan menjadi } \\
\text { lebih baik namun masih } \\
\text { terkalahkan oleh rasa malas. }\end{array}$ \\
\hline & $\begin{array}{l}\text { Pandangan } \\
\text { terhadap } \\
\text { konflik }\end{array}$ & $\begin{array}{l}\text { Responden menilai bahwa konflik } \\
\text { merupakan bagian dari hidup dan } \\
\text { pasti pernah dialami semua } \\
\text { manusia. Namun adanya konflik } \\
\text { bukan penyebab ketidakbahagiaan, } \\
\text { melainkan sebagai ujian dari Allah, } \\
\text { sebagai cara untuk menikmati hidup } \\
\text { serta sarana mengembangkan dan } \\
\text { memperbaiki diri }\end{array}$ & $\begin{array}{l}\text { Konflik hadir sebagai ujian atau } \\
\text { sarana mendapatkan ilmu }\end{array}$ & $\begin{array}{l}\text { Ada responden yang menyatakan } \\
\text { bahwa konflik memang ada dalam } \\
\text { kehidupan dan bisa membuat tidak } \\
\text { bahagia }\end{array}$ \\
\hline
\end{tabular}




\section{Kesimpulan}

Mayoritas responden dalam penelitian ini memiliki spiritual well-being (SpWB) yang tinggi. Responden yang memiliki spiritual well-being (SpWB) yang sedang belum dapat menikmati kehidupannya karena merasa masih memiliki banyak kekurangan diri. Responden dengan kategori SpWB tinggi merasakan adanya hubungan yang bermakna dengan Allah ditandai dengan selalu dilibatkannya Allah dalam segala aspek kehidupan mereka. Sedangkan pada responden dengan kategori SpWB sedang secara kualitatif ditandai dengan belum dirasakannya hubungan yang bermakna dengan Allah.

Responden yang memiliki skor spiritual well-being yang tinggi didominasi oleh metode menghafal dengan mengikuti lembaga tahfizh, memiliki jadwal yang tentatif (berubah-ubah), serta dorongan untuk menghafal Al-Qur'an bersumber dari dirinya sendiri. Sedangkan responden yang memiliki skor spiritual well-being yang sedang didominasi oleh responden yang jadwal menghafalnya tentatif (berubah-ubah) serta dorongan menghafal yang bersumber dari orang tua dan penghafal Al-Qur'an yang lain/idolanya. Fakta tersebut memunculkan kesimpulan hipotetis pada diri peneliti, bahwa motivasi intrinsik untuk menghafal dan keikutsertaan dalam lembaga pembimbing hafalan, merupakan faktor yang memiliki keterkaitan dengan SpWB.

\section{Saran}

Bagi peneliti selanjutnya yang tertarik dengan subjek penghafal Al-Qur'an, dapat melakukan penelitian terhadap subjek yang lebih spesifik misalnya santri pada institusi tahfidz tertentu atau anggota dari kelompok tahfidz tertentu, mempertimbangkan munculnya temuan bahwa keikutsertaan dalam lembaga tahfidz diduga berhubungan dengan variasi spiritual well-being.

Bagi responden penelitian, perbedaan perilaku yang muncul dapat menjadi referensi untuk refleksi diri dengan mengetahui perilaku apa saja yang dilakukan oleh orang-orang dengan SpWB tinggi, perilaku apa yang belum dilakukan oleh diri sendiri dan bisa dicoba dilakukan atau ditingkatkan dengan harapan dapat membuat SpWB diri sendiri menjadi lebih tinggi. 


\section{Kepustakaan}

B. Van Rooyen, and R. B. I. Beukes. Narrating Spiritual Well-Being in Relationship to Positive Psychology and Religion, 2009.

Darvyri, Panagiota, Michael Galanakis, Adamantios G Avgoustidis, Spyros Vasdekis, Artemios Artemiadis, Xanthi Tigani, and C Darviri. "The Spiritual Well-Being Scale (SWBS) in Greek Population of Attica." Psychology 5, no. 13 (2014): 1575-1582.

El-Menouar, Yasemin. “The Five Dimensions of Muslim Religiosity. Results of an Empirical Study." methods, data, analyses 8, no. 1 (2014): 26.

Hassan, Riaz. “On Being Religious: Patterns of Religious Commitment in Muslim Societies.” The Muslim World 97, no. 3 (2007): 437-478.

Hendricks-Ferguson, Verna. "Relationships of Age and Gender to Hope and Spiritual WellBeing among Adolescents with Cancer." Journal of Pediatric Oncology Nursing 23, no. 4 (2006): 189-199.

John W. Cresswell. Research Design Qualitative, Quantitative, and Mixed Methods Approaches, 2nd Edition. USA: Sage Publications Inc, 2003.

Kabar Makkah. “Ini 15 Fakta Mengapa Gerakan Menghafal Qur’an Di Indonesia Meningkat." Accessed June 25, 2016. http://www.kabarmakkah.com/2016/05/ini-15-faktamengapa-gerakan-menghafal-quran-berkembang-pesat.html?m=1.

Musa, Ahmad. "Spiritual Beliefs and Practices, Religiosity, and Spiritual Well-Being Among Jordanian Arab Muslim University Students in Jordan." Journal of Spirituality in Mental Health 17, no. 1 (2015): 34-49.

Naseer Butt. "Spiritual Well-Being in Relation to General Health among Kashmiri Students." Public Research (2013).

Nawaz, Nazia, and Syeda Farhana Jahangir. "Effects of Memorizing Quran by Heart (Hifz) on Later Academic Achievement." Journal of Islamic Studies and Culture 3, no. 1 (2015): 58-64.

R. M. Kaplan, and Demis P. Saccuzo. Psychological Testing: Principles, Application, and Issues, 5th Edition. Belmont: Wadsworth, 2001.

Raymond F. Paloutzian, and Crystal L. Park. Handbook of the Psychology of Religion and Spirituality. New York: The Guilford Press, 2005.

Republika. "Jumlah Penghafal Al-Qur'an Indonesia Terbanyak Di Dunia." Accessed June 25, 2016. http://www.republika.co.id/berita/dunia-islam/islam-nusantara/10/09/24/136336jumlah-penghafal-alquran-indonesia-terbanyak-di-dunia.

Rostiana. “Pengaruh Kebahagiaan Integratif Terhadap Komitmen Organisasional Dan Perilaku Kewargaan Organisasional." Disertasi, Universitas Padjajaran Bandung, 2011. 
Tuti A. Utama. “Perbedaan Kesejahteraan Spiritual Pasien Sebelum Dan Sesudah Operasi Jantung Di RSUP Dr. Hasan Sadikin Bandung." Tesis, Universitas Padjajaran Bandung, 2015. 